\section{MOLECULAR PHYSICS IN HIGH VACUA 1}

II.

THAVE hitherto spoken of and illustrated these phenomena in comnection with green phosphorescence. It does not follow, however, that the phosphorescence is always of that colour. This coloration is a property of the particular kind of glass in use in my laboratory. I have here (Fig. 7) three bulbs comgoseci of different glass: one is uranium glass $(a)$, which phos-

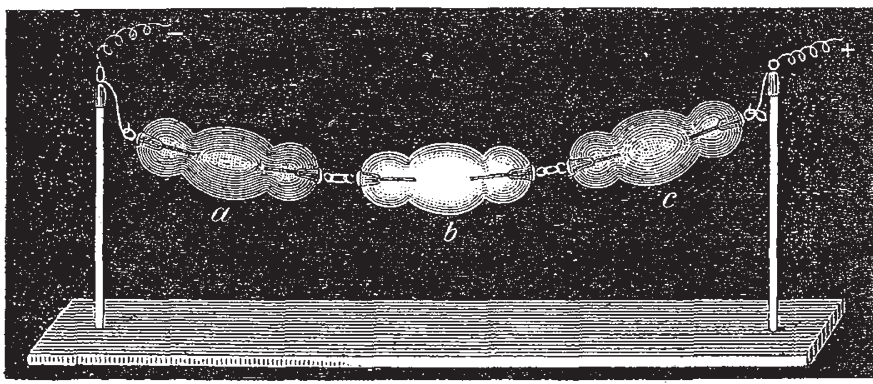

FIG. 7.

phoresces of a dark green colour; another is English glass (b), which phosphoresces of a blue colour; and the third $(c)$ is soft German glass-of which most of the apparatus before you is made-which phosploresces of a bright apple-green colour. It is therefore plain that this particular green phosphorescence is solely due to the glass which I am using. Were I to use English glass I should have to speak of blue phosphorescence, but I know of no glass which is equal to the German in brilliancy.

My earlier experiments were almost entirely carried on by the aid of the

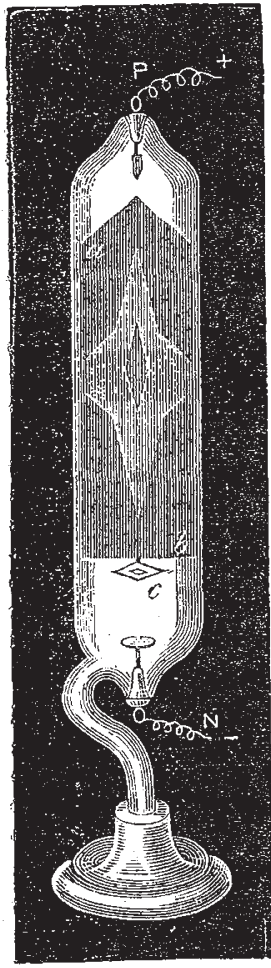

FIG. 8. thosphorescence which glass takes up electric discharge in vacuo; but many other substances possess this phosphorescent power, and some have it in a much higher degree than glass. For instance, here is some of the Iuminous sulphide of calcium prepared according to 'M. Ed. Becquerel's de. scription. When it is exposed to light - even candlelight-it phosphoresces for hours with a rich blue colour. I have jrepared a diagram with large letters written in this luminons sulphide ; before it is exposed to the light the letters are invisible, but Mr. Gimingham has just exposed it in mother room to burning magnesium, and now it is brought into the dark. ened theatre you will see the word " $\phi \hat{\omega} s, "$, light, a very suitable word for so beautiful a phosphorescenceshining brightly in luminous characters. The first letter, $\phi$, shines with an orange light; it is a sulphide of calcium pre pared from oyster-shells. The other letters, shining with a blue light, are sulphide of calcium prepared from precipitated carbonate of lime. Once the phosphorescence is excited the letters shine for several hours. I will put the diagram at the back, and we shall see how it lasts during the remainder of the lecture. This substance, then, is phosphorescent to light, but it is also much more strongly phosphorescent to the molecular discharge in a good vacuum, as you will see when I pass the discharge through this tube (Fig. 8). The white plate $(a, b)$ in the centre of the tube is a sheet of mica painted over with the luminous sulphide of which the letter $\phi$ was

I A short-hand report of a lecture delivered at the Royal Institution on Friday, Apr.1 4, 1879 . By William Crookes, F.R.S. Contributed by the author. Continued from p. 23 r composed in the diagram you have just seen. On connecting the poles with the coil, the mica screen glows with a strong yellowish green light, bright enough to illuminate all the appa ratus near it. But there is another phenomenon to which I now desire to draw attention: on the luminous screen is a lind of distorted star-shaped figure. A little in front of the negative pole I have fixed a star $(c)$ cut out in aluminium, and it is the mage of this star which you see on the screen. It is evident that the rays coming from the negative pole project an image of anything that happens to be in front of it. The discharge, therefore, must come from the pole in straight lines, and does not merely permeate ull parts of the tube and fill it with light as it would were the exhaustion less good. Where there is nothing in the way the rays strike the screen and produce phosphorescence, and where there is an obstacle they are obstructed by it, and a shadow is thrown on the screen. I shall have more to say about this shadow presently; I merely now wish to establish the fact that these rays driven from the negative pole produce a shadow.

I must draw your attention to an important ex periment connected with these molecular rays, but unfortunately it is a very delicate one, and very difficult to show to many at once; but I hope, if you know beforehand what to look for, you will all be able to see what I wish to show. In this pear-shaped bulb (Fig. 9A) the negative pole $(a)$ is at the pointed end. In the middle is a cross (b) cut out of sheet aluminium, so that the rays from the negative pole projected along the tube will be partly intercepted by the aluminium cross, and will project an image of it on the hemispherical end of the tube which is phosphorescent. I think you will all now see the shadow of the cross on the end of the bulb $(c, d)$, and notice that the cross is black on altminous

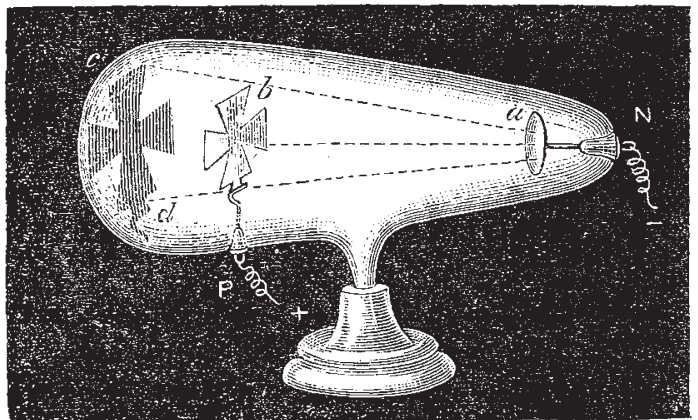

FrG. 9 A.

ground. Now, the rays from the negative pole have been passing by the side of the aluminium cross to prodnce the shadow; they have been hammering and bombarding the glass till it is appreciably warm, and at the same time they have been pro. ducing another effect on that glass-they have deadened its sensibility. The glass has got tired, if I may use the expression, by the ienforced phosphorescence. Some change has been produced

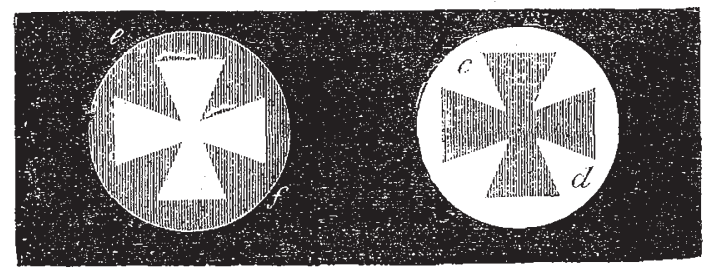

F1G. 9 B.

by this bombardment which will prevent the glass from responding easily to additional excitement; but the part that the sbadow has fallen on is not tired-it has not been phosphorescins at all, and is perfectiy fresh; therefore if $I$ throw this star down-I cin easily do. so by giving the apparatus a slight jerk, for it has been most ingeniously constructed with a hinge by $\mathrm{Mr}$. Gimingha!n-and so allow the rays from the negative pole to fall 
uninterruptedly on to the end of the bulb, you will suddenly see the black cross $(c, d, F i g .9 \mathrm{~B})$ change to a liminous one $(e, f)$, because the background is only faintly phosphorescing, whilst the part which had the black shadow on it retains its full phosphorescent power. The luminous cross is now dying out. This is a most delicate and venturous experiment, and I am fortunate in having succeeded so well, for it is one that cannot be rehearsed. After resting for a time the glass seems to partly recover its power of phosphorescing, but it is never so good as it was at first.

We have, therefore, found an important fact connected with

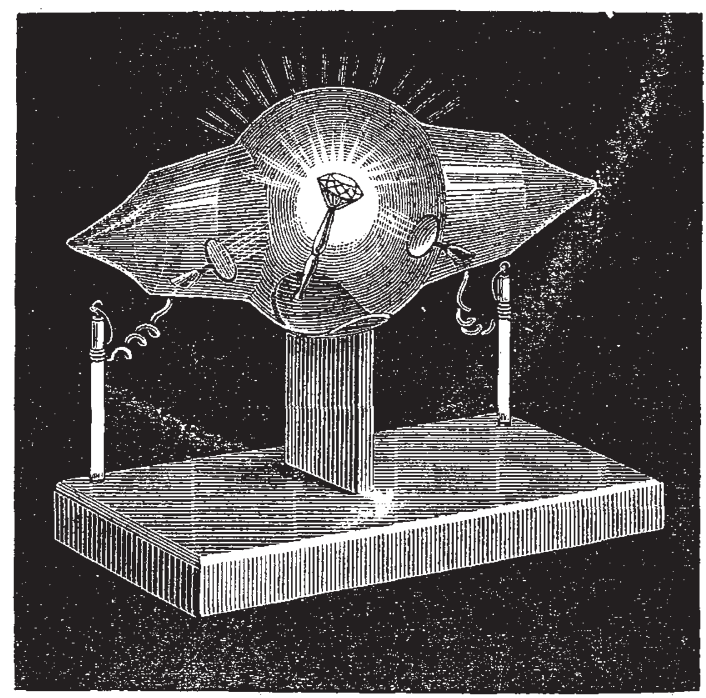

FIG. I

this phosphorescence. Something is projected from the negative pole which has the power of hammering away at the glass in front of it, in sucb a way as to cause it not only to vibrate and become temporarily luminous while the discharge is going on, but to produce an impression upon the glass which is permanent. The explanation which has gradually evolved itself from this series of experiments is this:-The exhaustion in these tubes is so high that the dark space, as I showed you at the commencement of this lecture, that extended round the negative pole, has widened out till it entirely fills the tube. By great rarefaction the mean free path has become so long that the hits in a given

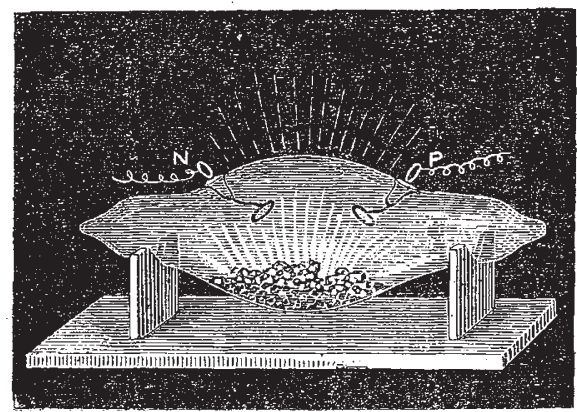

FIG. II

time may be disregarded in comparisen to the misses, and the average molecule is now allowed to obey its own motions or laws without interference. The mean free path is in fact comparable to the dimensions of the vessel, and we have no longer to deal with a continums portion of matter, as we should were the tubes less highly exhansted, but we must here contemplate the molecules individually. At first this u as only a convenient working hypothesis. Long-continued experiment then raised this provisional hypothesis almost to the dignity of a theory, and now the general opinion is that this theory gives a fairly correct explanation of the facts. In thesc highly exhausted vessels the mean free path of the reidual molecules of gas is so long that they are able to drive across from the pole to the other side of the tube with comparatively few collisions. The negatively electrified molecules of the gaseous residue in the tube therefore dash against anything that is in front, and cast shadows of obstacles just as if they were rays of light. Where they strike the glass they are stopped, and the production of light accompanies this sudden arrest of velocity.

Other substances besides English, German, and uranian glass, and Becquerel's luminous sulphides are also phosphorescent. I think, without exception, the diamond is the most sensitive substance I have yet met for ready and brilliant phosphorescence. I have here a tube, similar to those already exhibited, containing a mica screen painted with powdered diamond, and when I turn on the coil, the brilliant blue phosphorescence of the diamond can be seen, quite overpowering the green phosphorescence of the glass. Here, again, is a very curious diamond, which I was fortunate enough to meet with a short time ago. By daylight it is green, produced, I fancy, by an internal fluorescence. The diamond is mounted in the centre of this exhausted bulb (Fig. 10), and the negative discharge will be directed on it from below upwards. On darkening the theatre you see the diamond shines with as much light as a candle, phosphorescing of a bright green.

In this other bulb is a remarkable collection of crystals of diamonds, which have been lent me by Prof. Maskelyne. When I pass the discharge over them I am afraid you will only be able to see a few points of light, but if you will examine them after the lecture, you will see them phosphoresce with a most brilliant series of colours-blue, apricot, red, yellowish green, orange, and pale green

Next to the diamond the ruby is one of the most remarkable stones for phosphorescing. In this tube (Fig. II) is a collection of ruby pebbles, for the loan of which $I$ am indebted to my friend Mr. Blogg, of the frrm of Blogg and Martin, who placed a small sackful at my disposal. As soon as I turn on the induc. tion spark you will see these rubies shining with a brilliant rich red colour, as if they were glowing hot. Now the ruby is nothing but crystallised alumina with a little colouring-matter, and it became of great interest to ascertain whether the artificial ruby made by M. Feil, of Paris, would glow in the same man: ner. I had simply to make my wants known to M. Feil, and he immediately sent me a box containing artificial rubies and crystals of alumina of all sizes, and from those I have selected the mass in this tube which I now place under the discharge : they phosphoresce of the same rich red colour as the natural ruby. It scarcely matters what colour the ruby is, to begin with. In this tube of natural rubies there are stones of all coloursthe deep red ruby and the pale pink ruby. There are some s? pale as to be almost colourless, and some of the highly-prized tint of pigeon's blood; but in the vacuum under the negative discharge they all phosphoresce with about the same colour.

As I have just mentioned, the ruby is crystallised alumina. In a paper published twenty years a go by $\mathrm{Ed}$. Becquerel, ${ }^{I} \mathrm{I}$ find that he describes the appearance of alumina as glowing with a rich red colour in the phosphoroscope (an instrument by which the duration of phosphorescence in the sunlight can be examined). Here is some chemically pure precipitated alumina which I have prepared in the most careful manner. It has been heated to whiteness, and you see it glows with the rich red colour which is supposed to be characteristic of alumina. The mineral known as corunduin is a colourless variety of crystallised alumina. Under the negative discharge in a vacumm, corundum. phosphoresces of a rose-pink colour. There is another curions. fact in which I think clemists will feel interested. The sapphire. is also crystallised alumina, just the same as the ruby. The ruby has a little colouring-matter in it, giving it a red colour; the sapphire has a colouring-paatter which gives it a blue colour. whilst corundum is white. I have here in a tube a very fine crystal of sapphire, and, when I pass the discharge over it, it gives alternate bands of red and green. The red we can eavily identify with the glow of alumina ; but what is the green? If alumina is precipitated and purified as carefully as in the cace have just mentioned, but in a somewhat different mainer, it is found to glow with a rich green colour. Here are the two spe cimens of alumina in tubes, side by side. Chemists would say that there was no difference between one and the other; but 1 connect them with the induction-coil, and you see that one ylows with a bright green colour, whilst the other glows with a rick red colour. Here is a fine specimen of chemically pure a'iunion,

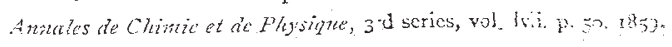


sent me by Messrs. Hophin and Williams; by ordinary light it is a perfectly white powder. It is just possible that the rich fire of the ruby, which has caused it to be so prized, may be due not entirely to the colouring-matter, but to its wonderful power of phosphorescing with a deep red colour, not only under the of phosphorescing with a dis discharge in a vacuum, but when-

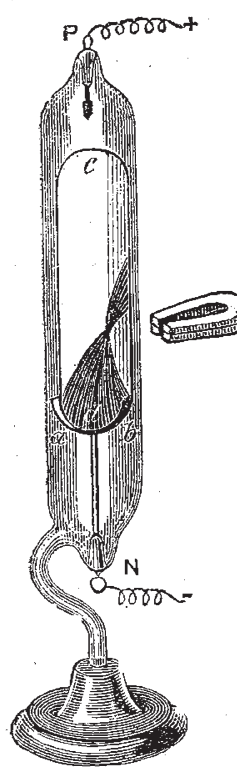

FIG. I2. ever exposed to a strong light.

The spectrum of the red light emitied by all these varieties of alumina--the ruby, corundum, or artificially precipitated a] $\mathrm{u}^{-}$ mina-is the same as described by Becquerel twenty years ago. There is one intense red line, a little below the fixed line $B$ in the spectrum, having a wave-length of about 6895 . There is a continuous spectrum beginning at about $B$, and a few fainter lines beyond it, but they are so faint in comparison with this red line that they may be neglected. This line may be called the characteristic line of alumina.

I now pass on to another fact connected with this negative discharge. Here is a tube (Fig. 12) with a negative pole $(a, b)$ in the form of a hemi-cylinder, similar to the one you have already seen ( $\mathrm{Fig} .3$ ), but in this case I receive the rays on a phosphorescent screen $(c, d)$. See how brilliantly the lines of discharge shine out, and how intensely the focal point is illu. minated; it lights the whole table. Now I bring a small magnet near, and move it to and fro; the rays obey the magnetic force, and the focus bends one way and the other as the magnet passes it. I can show this magnetic action a little more definitely. Here is a long glass tube (Fig. I3), very highly exhausted, with a negative pole at one end $(a)$ and a long phosphorescent screen $(b, c)$ down the centre of the tube. In front of the negative pole is a plate of mica $(b, d)$ with a hole $(e)$ in it,

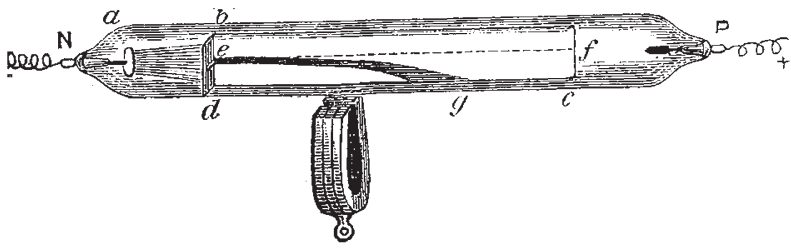

FIG. I3.

and the result is that when I turn on the current, a line of phosphorescent light $(e, f)$ is projected along the whole length of the tube. I now place beneath the tube a powerful horse-shoe tube. I now place beneath the tight becomes curved under the
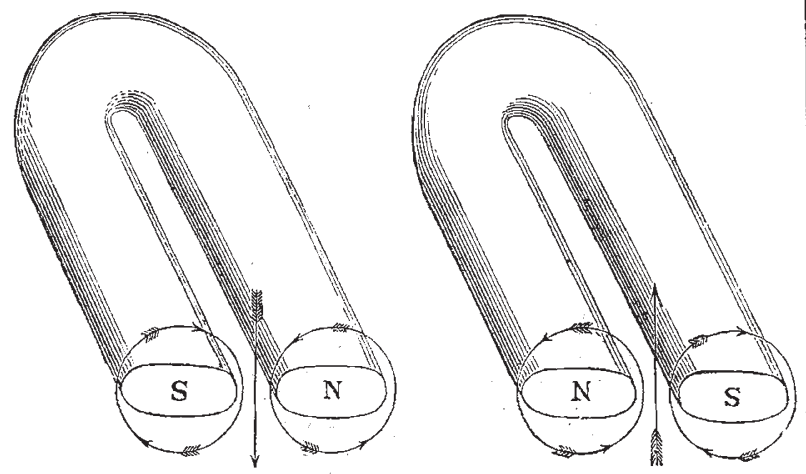

FiG. 14 .

magnetic influence $(e, g)$, waving about like a flexible wand as I move the magnet up and down. The action of the magnet can be understood by reference to this diagram (Fig. I4). The north pole gives the ray of molecules a spiral twist one way, and the south pole twists it the cther way; the two poles side by side compel the ray to move in a straight line up or down, along a plane at right angles to the plane of the magnet and a line joining its poles.

Now it is of great interest to ascertain whether the law governing the magnetic deflection of the trajectory of the molecules is the same as has been found is hold good at a lower vacuum. The former experiment was with a very high vacuum. This is a tube with a low vacuum (Fig. I5). On passing the induction spark it passes as a narrow line of violet light joining the two poles. Underneath I have a powerful electro-magnet. I make contact with the magnet, and the line of light dips in the centre towards the magnet. I reverse the poles, and the line is driven up to the top of the tube. Notice the difference between the two phenomena. Here the action is temporary. The dip takes place under the magnetic influence; the line of discharge then rises, and pursues its path to the positive pole. In the high exhaustion, however, after the ray of light had dipped to the magnet it did not recover itself, but continued its path in the altered direction.

During these experiments another property of this molecular. discharge has made itself very evident, although I have not yet drawn attention to it. The glass gets very warm where the green phosphorescence is strongest. The molecular focus on the tube, which we have just seen (Fig. I2) would be intensely hot, and I haye prepared an apparatus by which this heat at the focus can be intensified and rendered visible to all present. This small tube (a) (Fig. I6) is furnished with a negative pole in the form of a cup (b). The rays will therefore be projected to a focus in the middle of the tube (Fig. 17,a). At the side of the tube is a small electro-magnet, which I can set in action by touching a key, and the focus is then drawn to the side of the glass tube (Fig. I 7, b). To show the first action of the heat I have coated the tube with wax. I will put the apparatus in front of the electric lantern $(d)$, and throw a magnified image of the tube on the screen. The coil is now at work, and the focus of molecular rays is projected along the tube. I turn the magnetism on, and draw the focus on the side of the glass. The first thing you see

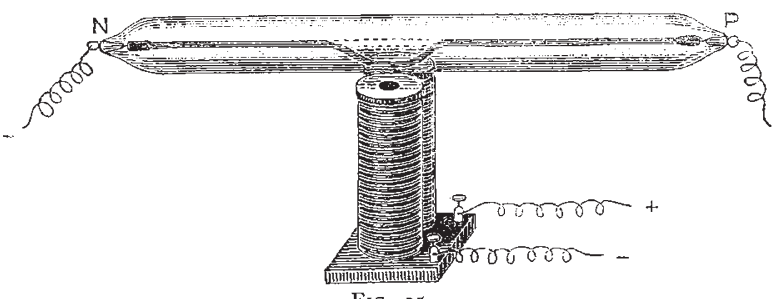

Fig. I5.

is a small circular patch melted in the coating of wax. The glass soon begins to disintegrate, and cracks are shooting starwise from the centre of heat. The glass is softening. Now the atmospheric pressure forces it in, and now it melts. A hole $(e)$ is perforated in the middle, the air rushes in, and the experiment is at an end.

Instead of drawing the focus to the side of the glass with a magnet, I will take another tube (Fig. 18), and allow the focus from the cup-shaped negative pole $(a)$ to play on a piece of platinum wire $(b)$ which is supported in the centre of the bulb. The platinum wire not only gets white-hot, but you can see sparks coming from it on all sides, showing that it is actually melting.

Here is another tube, but instead of platinum I have put in the focus that beautiful alloy of platinum and iridium which $\mathrm{Mr}$. Matthey has brought to such perfection, and I think that I shall succeed in even melting that. I first turn on the induction-coil slightly, so as not to bring out its full power. The focus is now playing on the iridio-platinum, raising it to a white heat. I bring a small magnet near, and you see I can deflect the focus of heat just as I did the luminous focus in the other tube. By shifting the magnet I can drive the focus up and down, or draw it completely away fr $\mathrm{mm}$ the metal, and render it non-luminous. I withdraw the magnet, and let the molecules have full play again ; the metal is now white-hot. I increase the intensity of the spark. The metal glows with almost insupportable brilliancy, and at last melts.

There is still another property of this molecular discharge, and it is this:-You have seen that the molecules are driven 
$\therefore$ lently from the nejative pole. If I place something in front $/$ in a more direct way? Nothing is simpler. I have only to put of these molecules, they show the force of impact by the heat some eacily moving object in the line of discharge in order to get which is produced. Can I make this mechanical action evident a powerful mechanical action. Mr. Gimingham, with great

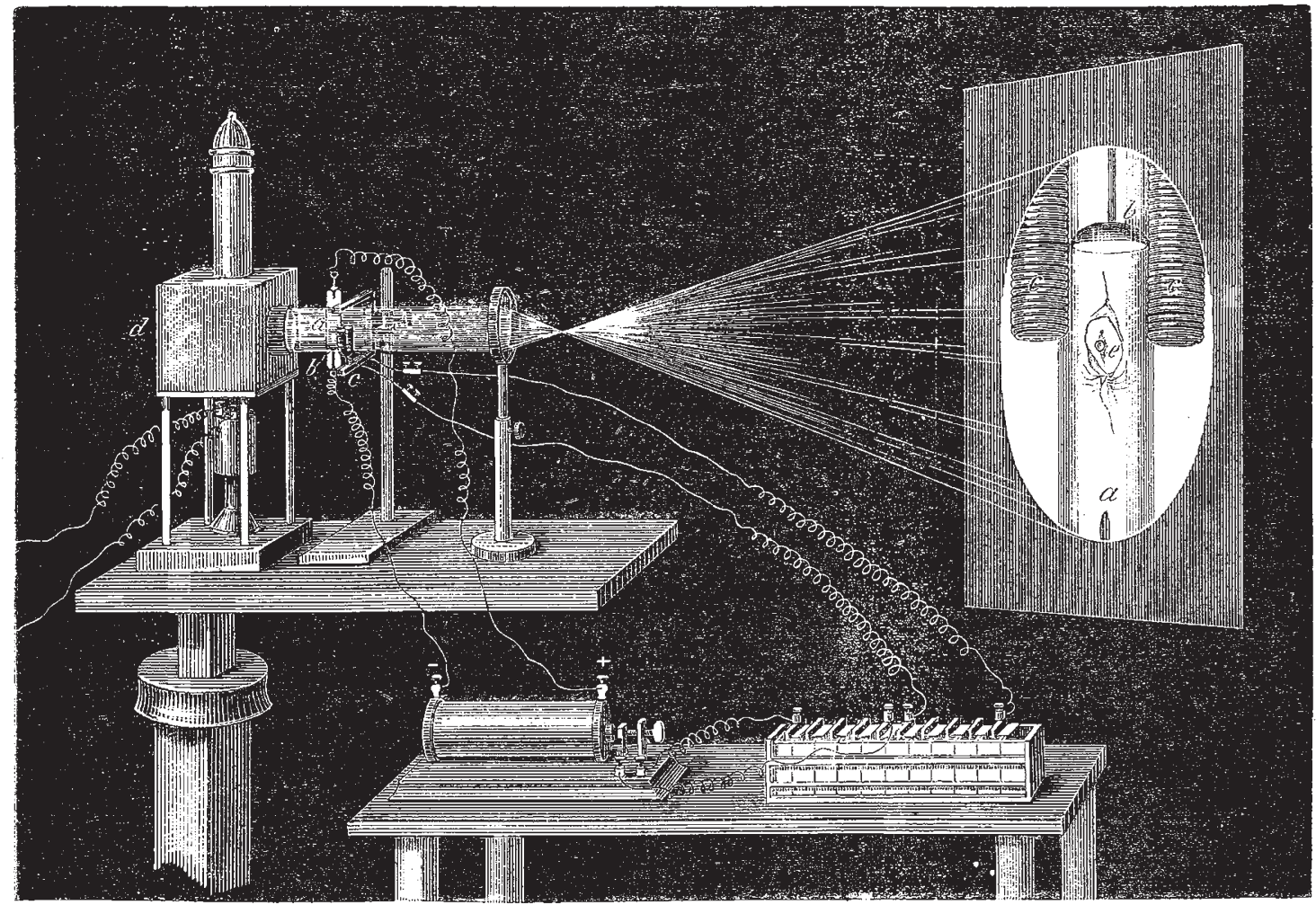

FIG. I5.

skill, has constructed a piece of apparatus which I will presently put in the electric lantern, so that all will be able to see its action. But frst I will explain the construction by means of this diagram (Fig. I9). The negative pole $(a, b)$ is in the form of "a very. shallow cup. In front of the cup is a mica screen

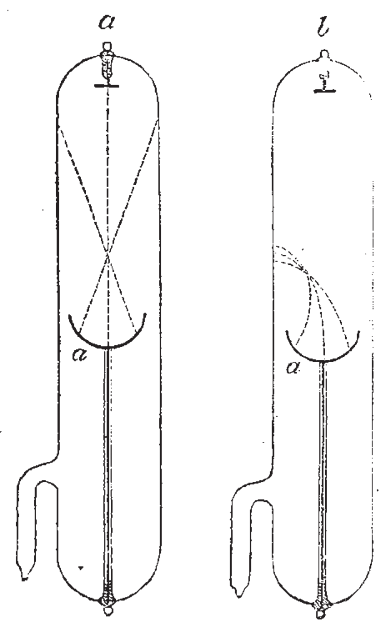

FIG. 27 .

(c, a), wide enough to intercept nearly all the molecular rays coming from the negative pole. Behind this screen is a mica wheel $(e, f)$ with a series of vanes, making a sort of paddle-wheel of it. So arranged, the molecular stream from the pole $a b$ will nearly all be cut off from the wheel, and what escapes over and mnder the screen will bit the vanes equally, and will not produce any movement. I now put a magnet, $g$, over the tube, so as to

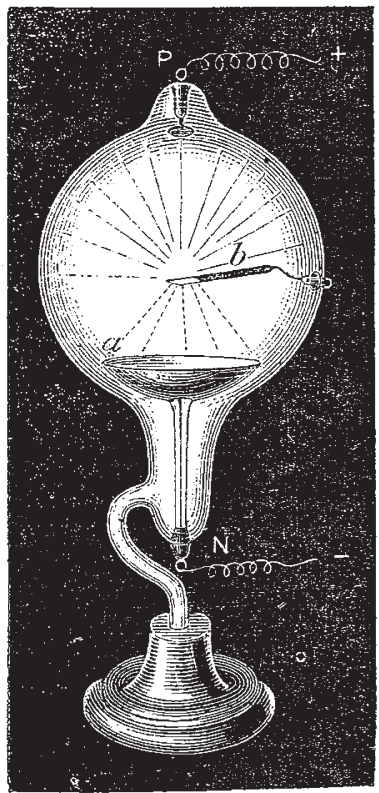

FเG. I8.

deffect the stream over or under the obstacle $c \dot{a}$, and the result will be rapid rotion in one or the other direction, according to 
the way the magnet is turned. I now throw the image of the appartus on the screen. The spiral lines painted on the wheel show which way it turns. I arrange the magnet to draw the molectlar stream so as to beat against the upper vanes, and the wheel revolves rapidly, as if it were an over-shot water-wheel. I now turn the magnet so as. to drive the molecular stream underneath; the wheel slackens speed, stops, and then begins to rotate the other way, as if it were an undershot water-wheel. This can be repeated as often as I like to reverse the position of the magnet, the change of rotation of the wheel showing immediately the way the molecular stream is deflected.

This experiment illustrates the last of the phenomena which time allows me to bring before you, attending the passage of the indiction spark through a highly exhausted atmosphere. It will now be naturally asked, What have we learned from the phenomena described and exhibited, and from the explanations that have been proposed? We find in these phenomena confirmation of the modern views of matter and energy. The facts elicited are in harmony with the theory that matter is not con. tinuous but composed of a prodigious number of minute particles, not in mutual contact. The facts also are in full accordance with the kinetic theory of gases - to which I have already re. ferred-and with the conception of heat as a particular kind of

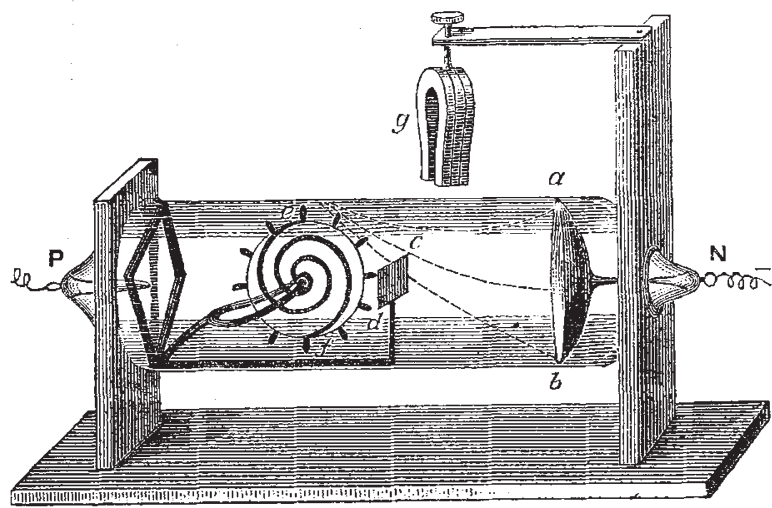

FIG. I9.

energy, expressing itself as a rapid vibratory motion of the particles of matter. This alone would be a lesson of no small value. In science every law, every generalisation, however well established, must constantly be submitted to the ordeal of a comparison with newly-discovered phenomena; and a theory may be pronounced triumphant when it is found to harmonise with and to account for facts which, when it was propounded, were still unrecognised or unexplained.

But the experiments have shown us more than this: we have been enabled to contemplate matter in a condition hitherto unlnown-in a fourth state-as far removed from that of gas as gas is from liquid, where the well-known properties of gases and elastic fluids almost disappear, whilst in their stead are revealed attributes previously masked and unsuspected. In this ultragaseous state of matter phenomena are perceived which in the mere gaseous condition are as impossible as in liquids or solids,

I admit that between the gaseous and the ultra-gaseous state there can be traced no sharp boundary; the one merges imperceptibly into the other. It is true also that we cannot see or handle matter in this novel phase. Nor can human or any other kind of organic life conceivable to us penetrate into regions where such ultra-gaseous matter may be supposed to exist. Nevertheless, we are able to observe it and experiment on it, legitimately arguing from the seen to the inseen.

Of the practical applications that may arise out of these researches, it would now be premature to speak. It is rarely given to the discoverer of new facts and new laws to witness their immediate utilisation. The ancients showed a perhaps unconscious sagacity when they selected the olive, one of the slowest growing trees, as the symbol of Minerva, the goddess of Arts and Industi: Nevertheless, I hold that all careful honest research will ultimately, even though in an indirect manner, draw after it, as Bacon said, "whole troops of practical applications."

\section{NOTES}

A MeEting of the Executive Committee having charge of the whole arrangements for the approaching visit of the British Association to Sheffield was held the other day. In connection with the Guide Book it was reported that contributions were arranged from Prof. Green, Mr. Arthur Jackson, Mr. F. Prittain, Mr. G. R. Vine, Mr. J. D. Leader, and others. It is proposed to issue the guide books at $I s$. each, and they will contain scientific and other information suitable for visitors and residents. Dr. Sorby stated that a number of eminent men from foreign countries, including representatives from Germany, Italy, France, Belgium, the United States, and other parts of the world, had accepted invitations to take part in the meetings in Sheffield. These distinguished visitors will represent different branches of science; and from France the British Association is this year to be honoured, after the lapse of a long period, with the presence of the President of the Academy of Sciences, M. Daubrée. The Mayor (Ald. Ward) is to give a banquet to a number of distinguished guests in the banqueting hall of the Cutlers' Company on Saturday, August 23. A reception is to be given by the Master Cutler and Cutlers' Company, which will take place in the Cutlers' Hall on 'Thursday, August 21. A soiréz is to be arranged by the local committee for the Tuesday following, also in the Cutlers' Hall. The arrangements for the excursions are being actively carried out. The Duke of Devonshire has invited a limited number of Members of the Association to a luncheon at Chatsworth. Earl Manners has invited a number of excur. sionists to luncheon at Thoresby, with the additional offer that they should be driven round the forest and park afterwards. Sir Joseph Whitworth has offered hospitality to a party of excursionists visiting Darley Dale and the district, and a similar offer has been made by Mr. F. C. Armitage, as regards a party ex ploring Arborlowe. The Rev. A. W. Hamilton-Gell invites a number of excursionists to Stanton-in-Peak, with the promise that they should see Router Rocks and other places of interest. Sir John Lubbock is to be asked to give an address at Arborlowe on the interesting Druidical remains there to be seen. Generally the arrangements were reported to be in a very satisfactory state.

SOME weeks since we stated that a committee had been formed for the purpose of raising a fund for the benefit of the widow and family of the late Mr. W. G. Valentin, F.C.S. We understand that many of the friends and former pupils of this well-known chemist have responded with liberality, but as there may be others whom previous appeals have not reached, we have pleasure in stating that subscriptions will still be received by the hon. treasurer of the fund, Mr. F. W. Bayly, Royal Mint, E.

THE success which attended Mr. Tegetmeier's reprint of Boddaert's "Table des Planches Enluminées," and Mr. Dresser's reproduction of Eversmann's Addenda to Pallas's "Zoographi Rosso-Asiatica," has suggested the organisation of a "Wil. loughby Society for the Reprinting of scarce Ornithological Works, "wich has accordingly been formed, with every prospect of success. The annual subscription is $I$., and no copies of the works reprinted will be sold. The selection of the works to be reprinted by the Society has been intrusted to a committee consisting of the past and present editors of The Ibis, and Tunstall's "Ornithologia Britannica" will be the first work reproduced. Particulars may be obtained from the secretary, F. D. Godman, Esq., ro, Chandos Street, Cavendish Square, W.

THE death is announced of Dr. Johann Karl Friedrich Rosenkranz, Professor of Philosophy at Koenigsberg University. Dr. Rosenkranz published a number of philosophical treatises, and was well known through his excellent edition of the works of Immanuel Kant. He died at the age of seventy four on June $14^{4}$ 